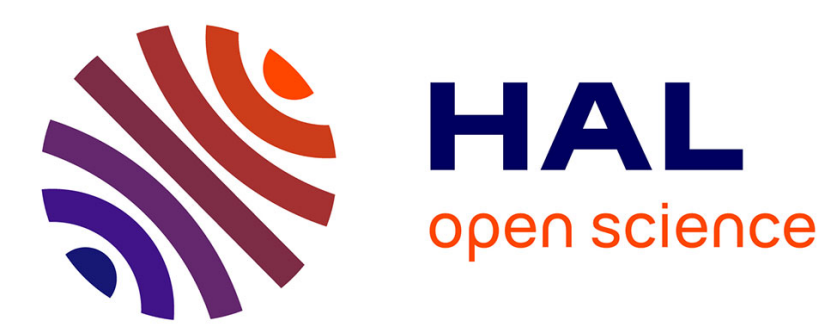

\title{
Life Cycle Assessment for Ordinary and Frost-Resistant Concrete
}

\author{
Ramin Sabbagh, Paria Esmatloo
}

\section{To cite this version:}

Ramin Sabbagh, Paria Esmatloo. Life Cycle Assessment for Ordinary and Frost-Resistant Concrete. IFIP International Conference on Advances in Production Management Systems (APMS), Sep 2019, Austin, TX, United States. pp.159-167, 10.1007/978-3-030-29996-5_19 . hal-02460516

\section{HAL Id: hal-02460516 https://hal.inria.fr/hal-02460516}

Submitted on 30 Jan 2020

HAL is a multi-disciplinary open access archive for the deposit and dissemination of scientific research documents, whether they are published or not. The documents may come from teaching and research institutions in France or abroad, or from public or private research centers.
L'archive ouverte pluridisciplinaire HAL, est destinée au dépôt et à la diffusion de documents scientifiques de niveau recherche, publiés ou non, émanant des établissements d'enseignement et de recherche français ou étrangers, des laboratoires publics ou privés. 


\title{
Life Cycle Assessment for Ordinary and Frost-resistant Concrete
}

\author{
Ramin Sabbagh and Paria Esmatloo \\ The University of Texas at Austin, Austin TX 78712, USA \\ \{sabbagh,p.esmatloo\}@utexas.edu
}

\begin{abstract}
This is an environmental study on concrete that follows the standard protocol of life cycle assessment (LCA) for two types of concrete, ordinary and frost-resistant concrete, with a focus on the superplasticizers used as admixtures. The use phase is not included in this study and the concrete is assumed to be inert during this phase. The results show that production of the raw material (especially cement) and the transports involved in the life cycle of concrete are the main contributors to the total environmental impacts. The environmental impact of frost-resistant concrete is between $24-41 \%$ higher than that of ordinary concrete due to its higher content of cement. Superplasticizers contribute with approximately $0.4-10.4 \%$ of the total environmental impact of concrete. Also, we have concluded that the low amount of leakage of superplasticizers from concrete leads to a low risk for the environment and humans.
\end{abstract}

Keywords: Life cycle assessment $\cdot$ LCA $\cdot$ Concrete

\section{Introduction}

The adverse environmental effects of global warming has concerned more and more people in the recent years. Global warming is the consequence of accumulation of the greenhouse gases such as $\mathrm{CO} 2, \mathrm{CH} 4$, etc. in the atmosphere as a result of human activities such as manufacturing and burning of fossil fuels. The concentration of $\mathrm{CO} 2$ is estimated to increase to over $800 \mathrm{ppm}$ by the end of the century [6]. From a globally sustainable perspective, careful speculation of environmental impacts such as global warming, energy consumption, and toxicity in manufacturing processes have become especially important.

Concrete is one of the world's most significant manufactured products with an average production of 1 ton per year [8]. Ordinary and frost resistant concrete are two if the most-used types of concrete. Frost-resistant concrete is mainly used in the construction of bridges and dams. The life cycle assessment or LCA is a method used to evaluate the environmental impact from the entire life cycle of a product, from "the cradle to the grave" [13]. Cradle to grave begins with the gathering of raw materials from earth to create the product and ends at the point all materials are returned to the earth. In a nutshell, LCA is a technique to assess the environmental aspect and potential impacts associated with 
a product, process, or service by compiling an inventory of relevant energy and material inputs and environmental releases, evaluating their potential impacts, and interpreting the results to help make a more informed decision. The four main phases of LCA process are goal definition and scoping, inventory analysis, impact analysis, and interpretation [12]. In this paper, we conduct life cycle assessment of ordinary and frost-resistant concrete from cradle to grave. We evaluate the energy consumption as well as different types of emissions for each stage of concrete's life.

\section{Composition of Concrete}

The main ingredients in concrete are aggregate (70-80\%), cement (10-20\%) and water (7-9\%), and to enhance specific characteristics, chemical admixtures (less than $1 \%$ ) are added.

Cement is a hydraulic binder, which hardens when it is mixed with water [7]. To produce cement the limestone and clay are ground together. The calcination process begins when the material passes from the kiln to the calcinator : $\mathrm{CaCO} 3$ + heat $\rightarrow \mathrm{CaO}+\mathrm{CO} 2$, which accounts for most of the energy used in cement production [3]. The last step in cement production is the grinding together of the cement clinker and gypsum. After finishing and packaging, the cement is transported to cement depots [7].

Aggregate is either macadam or gravel. To optimize its function aggregate of all sizes should be included in the concrete [3]. Macadam is used to a greater extent since natural gravel is a more limited resource. The proportion of natural gravel to macadam also depends on the location.

There are two types of admixtures, chemical and mineral. Mineral admixtures such as fly ash and silica powder are not analyzed here. Chemical admixtures included in the analysis are air-entraining admixtures and superplasticizers. Airentraining admixtures create numerous small air bubbles in the concrete, which expand interstitial water when the temperature drops below freezing and prevent the concrete from cracking. In unhardened concrete the admixture prevents water separation and increases the workability [3]. Superplasticizers are used to drastically reduce the amount of water (up to $30 \%$ ) in concrete and still keep the same consistency of un-hardened concrete [10]. This leads to higher strength, lower permeability and higher durability [3]. Normal plasticizers can reduce the water content up to $8-10 \%$. The superplasticizer used in the recipes in this paper is called Peramin F and is based on sulphonated melamine formaldehydes [4].

\section{Methodology for LCA}

In this study the whole life cycle of concrete will be considered, starting with the exploitation of the raw materials and ending with the recycling or disposal of the demolished concrete, considering the (positive) impact of avoiding the use of natural raw materials. The environmental impact of the application field and repair of the structure are considered into the functional unit which considers 


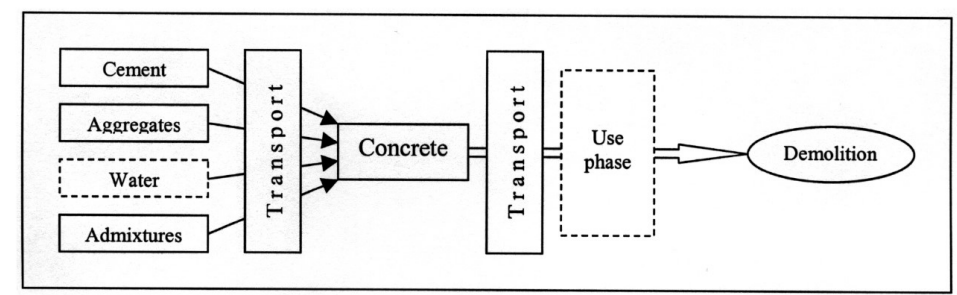

Fig. 1: General Flowchart for Concrete Life Cycle

the strength and durability performance of the concrete mixtures. However, the environmental impact related to the use phase is not considered [5].

The results of this study are presented both per $\mathrm{kg}$ material for each raw material and per functional unit (FU) which is equivalent to $1 \mathrm{~m}^{3}$ of concrete. The phases of the life cycle of concrete are shown in Figure 1. Casting is excluded because of difficulties in gathering data. The impact assessment categories included are energy use, Global Warming Potential (GWP), Eutrophication Potential (EP), Acidification Potential (AP), Photochemical Oxidant Creation Potential (POCP) and toxicity of superplasticizers.

Impact assessment $=$ Inventory loadings $\times$ Characterization factor

A life cycle inventory analysis quantifies the energy, material inputs, and emissions during aggregate extraction, concrete production, and other life cycle phases. Data from each phase of life cycle analysis were collected from peer reviewed journals and websites. For instance, Cement production data is collected from Cementa $\mathrm{AB}$ company, gravel production are taken from an existing LCA report, superplasticizer data are extracted from an EPD by the European Federation of Concrete Admixture Associations (EFCA), data for concrete production are taken from environmental reports from two factories in the group of Sydsten AB, transportation data are taken from NTM [15], and demolition data are collected by personal communication with a subcontractor to gab Syd/Sysav. Transportation data are taken from NTM [15]. The proportions of the components in the two types of concrete are shown in Table 1.

The overall density of concrete is $2400 \mathrm{~kg} / \mathrm{m}^{3}$ and this value is used in this study. Inventory results for the superplasticizer, Peramin F, are valid for four main groups of superplasticizers: sulphonated naphthalene formaldehyde, sulphonated melamine formaldehyde, vinyl copolymers and poly-carboxylic ethers [4]. The air-entraining admixture, Peramin HPA, used in the recipes contains sulphonates and alkyl alcohols [4]. Since LCI data were not available for the air-entraining admixture the data for superplasticizers are used instead.

Life Cycle Inventory In this section we detail the process for calculation of Life Cycle Inventory (LCI) data for two types of concrete [13] used in this study.

The amounts of the various ingredients utilized in cement production have been collected from Cementa ABs report. The three main ingredients are lime- 
stone, sand and gypsum. To produce $1 \mathrm{~kg}$ cement, $1.4 \mathrm{~kg}$ limestones, $70 \mathrm{~g}$ sand, and $30 \mathrm{~g}$ gypsum should be mixed [2]. The impact of limestone quarrying is assumed to be the same as that of macadam production. The impact of sand production is the same as that of gravel production [14]. Fuels used in the production of cement are coal and coke. The emissions from the use of these fuels are presented as a total sum in the production of the cement at the factory. Emissions from the production and distribution of these fuels are calculated separately and both coal and coke are regarded as coal [1]. Transports of the raw material to the location of cement production are not taken into consideration as they are mostly situated in the vicinity of the cement production facility. LCI data such as energy use and emmision to air and water for production of $1 \mathrm{~kg}$ cement, $1 \mathrm{~kg}$ gypsum are found from [11]. Energy contents for coal, or alternative fuels such as car tires and bone meal can be extracted form [11] as well.

In Macadam production, Diesel is used for internal transports, approximately $0.5 \mathrm{~L} /$ ton macadam while the stone crusher uses electricity, approximately 9 $\mathrm{kWh} / \mathrm{ton}$. The diesel density was $815 \mathrm{~kg} / \mathrm{m}^{3}$ and the energy content was 43.2 $\mathrm{MJ} / \mathrm{kg}$ [1]. In the extraction of gravel a wheel loader is used to excavate the gravel, while the internal transports use lorry loaders [14]. Finally LCI data is found for aggregate by adding up the data energy use and emission to air and water for gravel production [14] and macadam production.

Data for the production of superplasticizer is from [4]. Energy content for coal is 27.2 , for crude oil is 42.7 , and for natural gas is $51.9 \mathrm{MJ} / \mathrm{kg}$ [11]. Inventory results associated with superplasticizer are presented in [4]. In the fabrication of concrete only electricity is used, $32.7 \mathrm{MJ} / \mathrm{m} 3$, while oil is used for heating the plant, $1.5 \mathrm{E}-05 \mathrm{MJ} / \mathrm{m} 3$ concrete. Energy content of oil is $39 \mathrm{GJ} / \mathrm{m}^{3}$ [11]. The energy needed for demolition is estimated to vary between $0.006-0.008 \mathrm{MJ} / \mathrm{kg}$ concrete, with an average of $0.007 \mathrm{MJ} / \mathrm{kg}$ [13].

The transportation vehicles used in the study are heavy trailers, mediumheavy trailers and medium-sized ships. The transports for the raw materials and concrete produced are by trucks; either heavy trucks or medium heavy trucks except for the transport of cement to depot, which is by ship. Cement and admixtures are both transported by heavy trucks. Aggregate, i.e. macadam and gravel, is often produced near the concrete factory and is therefore transported by a medium heavy truck. Ready-mixed concrete is transported in a liquid-

Table 1: Proportions for two types of concrete

\begin{tabular}{|l|c|c|c|c|}
\hline & \multicolumn{2}{|c|}{ Ordinary concrete } & \multicolumn{2}{|c|}{ Frost-resistant concrete } \\
\hline Components & $\mathrm{kg} / \mathrm{m}^{3}$ & $\%$ & $\mathrm{~kg} / \mathrm{m}^{3}$ & $\%$ \\
\hline Cement & 295 & 13 & 434 & 18 \\
Macadam & 749 & 32 & 951 & 40 \\
Natural gravel & 1093 & 47 & 828 & 35 \\
Superplasticizer (Peramin F) & 1.51 & 0.06 & 0.95 & 0.04 \\
Air-entraining admixture (Peramin HPA) & 0 & 0 & 3.3 & 0.1 \\
Total amount of water & 202 & 8.6 & 167 & 7 \\
\hline
\end{tabular}


concrete carrier, which is assumed to have the same characteristics as a medium heavy truck. Data for transportation are gathered from MTN.

\section{Life Cycle Impact Assessment and Results}

We convert all emissions to appropriate equivalent emissions in order to calculate the environmental impacts according to [11]. Then the values are added together to find out the final amount of specific environmental impact.

Global Warming Potential The production of the raw material is the main contributor to the global warming potential (GWP) in the concrete life cycle. It causes approximately $8 \%$ of the total GWP. Within raw materials, cement production causes the largest greenhouse-gas emissions due to the calcination process in the cement factory [13]. Approximately $69 \%$ of the CO2 emissions from the factory come from the calcination and the remaining $31 \%$ come from the fossil fuels used. The calcination process is necessary since it is the clinker mineral that reacts in the hydration process. But it is possible to replace a part of the clinker mineral by ground limestone that is not calcinated, as in construction cement. Another way of reducing CO2 emissions is to replace fossil fuels by renewable fuels.

Eutrophication Potential Transports are the main contributor to the eutrophication potential (EP), approximately 59-65\% (for ordinary and frost-resistant concrete respectively) of the total $\mathrm{EP}$, and the reason for this is foremost the transportation of the concrete, followed by the transportation of cement from factory to depot. Also the production of the raw material has a significant impact on the EP, mostly because of the production of cement, which causes high emissions of NOx.

Acidification Potential Transports contribute approximately $61-66 \%$ to the total acidification potential (AP). The transport of concrete has the highest impact, closely followed by the transport of cement from factory to depot. The production of raw materials also contributes to the AP, mainly in the production of cement.

Photochemical Oxidant Creation Potential Transports are also the main contributor to the photochemical oxidant creation potential (POCP), namely, by $58-68 \%$ and of this the transportation of the concrete has the highest impact. Of the impact due to raw material production it is the production of the cement (64-76\% of the raw material production) and the superplasticizers (20-25\% of the raw material production) that are the main contributors.

Energy Consumption Cement production has the highest energy demand both as electricity and fossil fuels. Superplasticizers use $2 \%$ of both electricity and fossil fuel in ordinary concrete and $4 \%$ of electricity and $3 \%$ fossil fuel in frost-resistant concrete. 

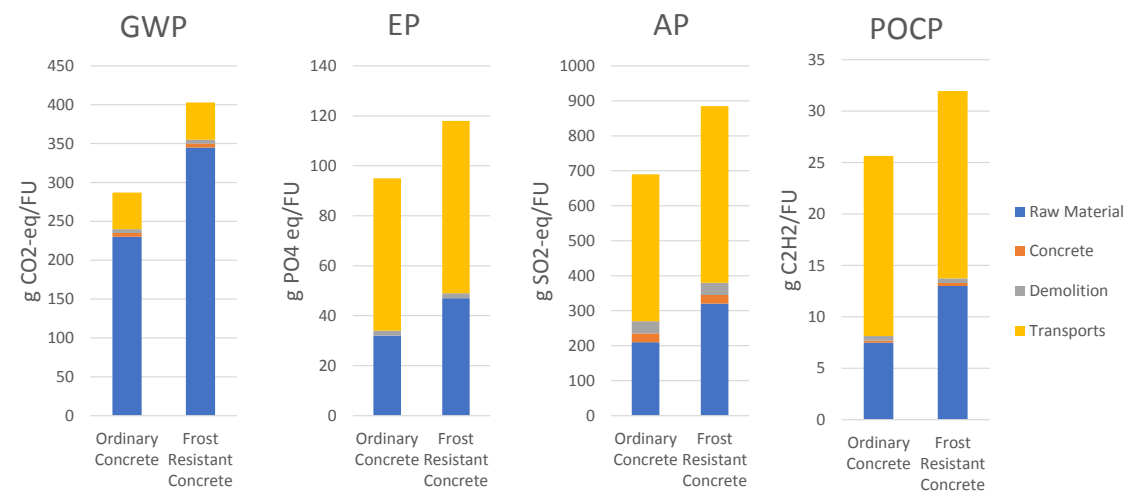

Fig. 2: Difference in impact between the different stages in the concrete life cycle. The left-hand column is for ordinary concrete, the right-hand column for frost-resistant concrete.

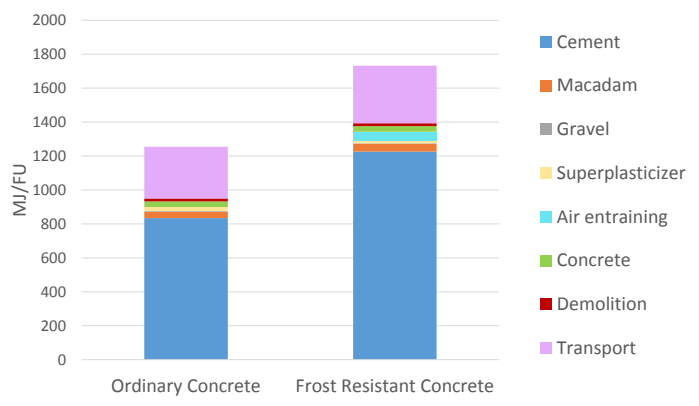

Fig. 3: Energy demand for production of ordinary and frost-resistant concrete

Toxicity The European Federation of Concrete Admixture Associations has made a study regarding the impact of concrete admixtures on the environment. The authors identified the greatest pollution as originating in emissions from concrete demolition material. Wastewater treatment and appropriate handling can avoid other sources [9].

Our study show that approximately $15-25 \%$ of sulphonated naphthalene polymers (SNP), lignosulphonate and polycarboxylates and $30-60 \%$ of sulphonated melamine polymers (SMP) were leached in a worst-case scenario. This might seem much but in an additional test they established that it is only a part of the total leached organic substances that comes from superplasticizers, the rest comes from other products used in the construction such as coatings and adhesives. It is not the original products which are leached but their degradation products, i.e. if SNP are used then it will be mostly naphthalene sulphonate monomers which are leached. The degradation products are more biodegrad- 
able than the original substances. The conclusion of the study is that leakages of superplasticizers from crushed concrete will not cause any adverse effects on humans or the environment if the superplasticizer and the product are handled correctly. Concrete admixtures are water-soluble and will not accumulate in, for example, soils and organisms [9].

\section{Conclusion and Implications}

This study shows that it is the raw material production (concerning GWP) together with the transportation operations (concerning EP, AP and POCP) that are the main contributors to the environmental impact of concrete (Figure 2). Within the transport operations it is the transport of the concrete, by mediumheavy truck, followed by the transport of the cement to the depot, by ship, that make the largest contribution compared to short distances for transport of raw materials. When the transport distances were reduced by $40 \%$ the environmental load from transport operations decreased to approximately the same level as for the raw material production. Transportation by ship has the smallest impact per ton kilometer and covers the longest distance.

Superplasticizers make a contribution of $0.4 \%$ of GWP, $0.7 \%$ of EP, $2.1 \%$ of $\mathrm{AP}$ and $6.0 \%$ of $\mathrm{POCP}$ in ordinary concrete. The corresponding ratios for frostresistant concrete are $0.6 \%, 1.3 \%, 3.6 \%$ and $10.4 \%$. Thus, superplasticizers have a limited environmental impact in concrete and, according to three independent studies, there is only a low risk of toxic effects due to leakage of superplasticizers from demolition materials.

Frost-resistant concrete has a larger environmental impact per $\mathrm{m}^{3}$ than ordinary concrete since it has a higher content of cement, a large contributor in raw material production and transport operations. Frost-resistant concrete requires $38 \%$ more electricity and $45 \%$ more energy in the form of fossil fuel per $\mathrm{m}^{3}$ compared to ordinary concrete. The contribution to the GWP, frostresistant concrete is $41 \%$ higher, to the EP $24 \%$ higher, to the AP $30 \%$ higher and to the POCP $25 \%$ higher per $\mathrm{m}^{3}$ than ordinary concrete. Even though the frost-resistant concrete has a higher environmental impact and energy demand, these are not the only aspects that have to be considered in construction. Frostresistant concrete is often used in constructions, such as bridges and dams, which have particularly high requirements in durability.

As concluded above, the environmental load from superplasticizers in concrete is small. In the production of superplasticizers, however, crude oil and natural gas are used both as raw material and as fuel. Thus, to reduce the environmental impact of superplasticizers in the concrete not only the raw materials have to change but also the way of production. From a system perspective, it is important that adding superplasticizers also leads to indirect environmental benefits since the amount of water needed in the concrete reduces by approximately $30 \%$, leading to reduced transportation needs of ready-mixed concrete. Without the superplasticizers, the concrete would contain approximately 9-11\% of water, compared to $7-9 \%$ with superplasticizers. This reduction may seem 
small in itself but when considering the volumes of concrete used, it makes a noticeable difference [13].

Calculations show that there is a linear ratio between transport distances and environmental impact. In this study, the transport operations are calculated to stand for twice as much environmental impact as the raw material production. If the transport distances are reduced by $40 \%$ the environmental impact between raw material production and transports becomes almost equal. Moreover, as seen in previous calculations, shipment transportation is more efficient and has less environmental impact. It is better to change the way of transportation from trucks to ship transports. Another way of reducing environmental impacts is using renewable energies in different stages of concrete life cycle. The most important phase is transportation. If we could change the energy sources from fossil fuels to renewable energies such as solar energy, it would lead to less environmental issues and impact.

\section{References}

1. Bernesson, S.: Farm-scale production of rme and ethanol for heavy diesel engineswith emphasis on environmental assessment (2004)

2. Björklund, T., Tillman, A.J.: Lca of building frame structures : environmetal impact over the life cycle of wooden and concrete frames (1997)

3. Burström, P.G.: Byggnadsmaterial: uppbyggnad, tillverkning och egenskaper (2: a uppl.). Studentlitteratur AB (2007)

4. BV, E.C.I.: Environmental declaration superplasticizing admixtures (2002)

5. De Schepper, M., Van den Heede, P., Van Driessche, I., De Belie, N.: Life cycle assessment of completely recyclable concrete. Materials 7(8), 6010-6027 (2014)

6. Feely, R.A., Sabine, C.L., Lee, K., Berelson, W., Kleypas, J., Fabry, V.J., Millero, F.J.: Impact of anthropogenic co2 on the caco3 system in the oceans. Science 305(5682), 362-366 (2004)

7. Johansson, S.: Cement in betonghandbok material. Edited by Ljungkrantz, Möller \& Petersons, AB Svensk byggtjänst, Solna (1994)

8. Lippiatt, B., Ahmad, S.: Measuring the life-cycle environmental and economic performance of concrete: the bees approach. In: Proceedings of the International Workshop on Sustainable Development and Concrete Technology. pp. 213-230 (2004)

9. Maeder, U., Gaelli, R., Ochs, M.: The impact of concrete admixtures on the environment. Construction Chemicals, SIKA Technolgies AG BMG Engineering AG, Schlieren, Swithzerland (2004)

10. Ramachandran, V.S., Malhotra, V., Jolicoeur, C., Spiratos, N.: Suplerplasticizers: properties and applications in concrete (1998)

11. Rydh, C.J., Lindahl, M., Tingström, J.: Livscykelanalys-en metod för miljöbedömning av produkter och tjänster. Studentlitteratur, Lund, Sweden (2003)

12. (SAIC), S.A.I.C., Curran, M.A.: Life-cycle assessment: principles and practice. National Risk Management Research Laboratory, Office of Research and (2006)

13. Sjunnesson, J.: Life cycle assessment of concrete (2005)

14. Stripple, H.: Life cycle assessment of road: a pilot study for inventory analysis. IVL RAPPORT (1210) (2001)

15. Swahn, M.: Nätverket för transporter och miljö (ntm), head of the ntm board (2007) 